\title{
Pattern of skin diseases and common drugs prescribed in dermatology outpatient department of Kathmandu Medical College Teaching Hospital, Duwakot
}

\section{Shrestha B' ${ }^{1}$, Shrestha PR ${ }^{2}$}

${ }^{1}$ Binaya Shrestha, Assistant Professor, Department of Pharmacology; ${ }^{2}$ Prashanna Raj Shrestha, Lecturer, Department of Dermatology; Kathmandu Medical College and Teaching Hospital, Duwakot, Bhaktapur, Nepal.

\begin{abstract}
Background: There is a wide variation in the pattern of skin diseases in different countries and the pattern even varies across different parts within the same country. For the treatment purpose different classes of drugs and combinational products are widely used in dermatology. Periodic prescription analysis in the form of drug utilization study can improve the quality of prescription and decrease irrational prescribing.

Objectives: The objective of the study was to find the pattern of skin diseases and the common group of drugs prescribed in Kathmandu Medical College Teaching Hospital at Duwakot.

Methodology: A prospective, observational, single center study was conducted at Dermatology outpatient department of Kathmandu Medical College Teaching Hospital at Duwakot, from December 2018 to June 2019 and a total of 300 prescriptions were collected during the study period. The data were collected from patient card and details were filled in the predesigned proforma.

Results: A total of 300 prescriptions were collected and analyzed for demographic profile, disease incidence and drug prescription. Most common condition observed were dermatitis 50 (16.7\%), tinea $43(14.3 \%)$, urticaria 31 (10.3\%). Antihistaminics (28.7\%), corticosteroids (16.9\%) antibiotics (14.8\%), antifungals (14.8\%) were the most common class of drugs prescribed. Drugs prescribed were mainly given by topical route $(50.6 \%)$ followed by oral route.

Conclusion: The current study revealed that the mean number of drugs/prescriptions was slightly higher than the recommended limit of two approved by world health organization and the practice of poly-pharmacy was occasionally seen.
\end{abstract}

Key words: Antibiotics; Antihistaminics; Dermatitis; Skin diseases; Tinea

DOI: https://doi.org/10.3126/jkmc.v8i3.29719

\section{INTRODUCTION}

kin is the largest organ in the body and has many functions. It functions as the first line of defense against radiation, harmful pollutants, and microbial infections. However, sometimes skin tends to become affected by various diseases. Skin diseases are common clinical entities. Patterns of skin diseases are different from one country to another and also show variation within the different part of the same country'.

Address for correspondence

Dr. Binaya Shrestha

Department of Pharmacology,

Kathmandu Medical College and Teaching Hospital,

Duwakot, Bhaktapur, Nepal

E-mail: binaya110@yahoo.co.uk

ORCID: https://orcid.org/0000-0002-3507-6131
In developing countries like Nepal, skin diseases have a serious impact on people's quality of life. Most widely observed problems in developing countries are allergy and itching conditions ${ }^{2}$. Public awareness regarding personal hygiene and healthy living is necessary to reduce the burden of skin diseases and for improved quality of life in people especially in developing nations. The drugs prescribed are not necessarily based on patient needs and patient needs are not necessarily met with drug therapy. However, there is as much concern about inappropriate and expensive prescribing.

Drug utilization studies have been the powerful exploratory tools to ascertain the role of drugs in the society and hence become an essential part of pharmaco-epidemiology providing the insights into 
various aspects of drug prescribing. Since no such study has been conducted previously in Duwakot, we have planned to conduct this study. The data of the current study will give the information about the prevalence of skin diseases and the common drugs prescribed for their treatment.

\section{METHODOLOGY}

A prospective, observational, single center study was conducted at Dermatology OPD of Kathmandu Medical College and Teaching Hospital (KMCTH), Duwakot from December 2018 to June 2019 and a total of 300 prescriptions were collected during the study period. The data was collected by random sampling technique. The study included patients of all age group and both sexes suffering from various skin diseases and who are willing to participate in the study. Those patients who have to be referred to other department or who are not willing to participate in the study were excluded. Once the consultations from the dermatologists were over, the data relevant to the study such as type of skin diseases, demographic profile of the patient, drug prescribed, dosage form, frequency, route of administration, duration of treatment were collected from patient OPD card and filled in predesigned proforma. The patient details were not disclosed to any other party other than co-investigator.

An approval from the Institutional Review Committee of Kathmandu Medical College Teaching Hospital was obtained before starting the study. The data collected were recorded in Microsoft office excel and double checked before further analysis. For analysis SPSS (Statistical Package for Social Science) software version 25 was used. Data were presented in the form of frequency, percentages, mean and standard deviation.

\section{RESULTS}

A total of 300 OPD prescriptions were collected and analyzed for demographic profile, disease incidence and drug prescription. The demographic profile of the patients is shown in figure 1.

Dermatitis was found to be the most common skin disease 50(16.7) followed by tinea 43 (14.3\%), urticaria $31(10.3 \%)$, acne 19(6.3\%) and scabies 13(4.3\%) which is shown in table 1. Antihistaminics was the most frequently prescribed group of drugs in this study.

Table 2 shows that the frequency of antihistaminics prescribed was 209 (28.7\%), followed by corticosteroids, antibiotics, and antifungals. Topical route was the preferred route of drug administration followed by oral route as shown in figure 2 .

Among the drugs given by the topical route, cream was found to be the commonest dosage form whereas tablet was the most preferred dosage form for oral route. In this study, it was also observed that the mean number of drugs per prescription is $2.42 \pm 0.82$ and the minimum and maximum number of drugs per prescription is $1 \& 5$ respectively.

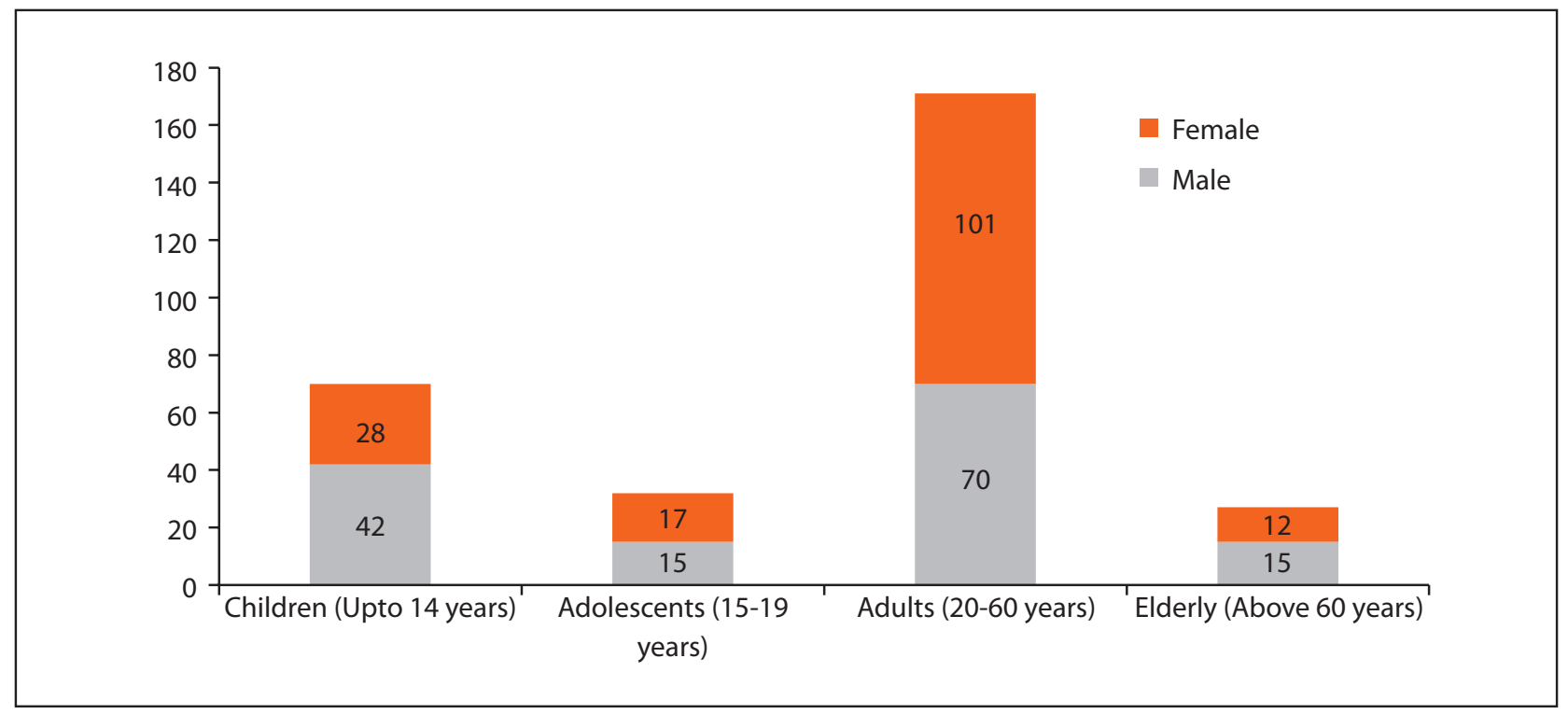

Figure 1: Demographic profile of the patients $(n=300)$ 


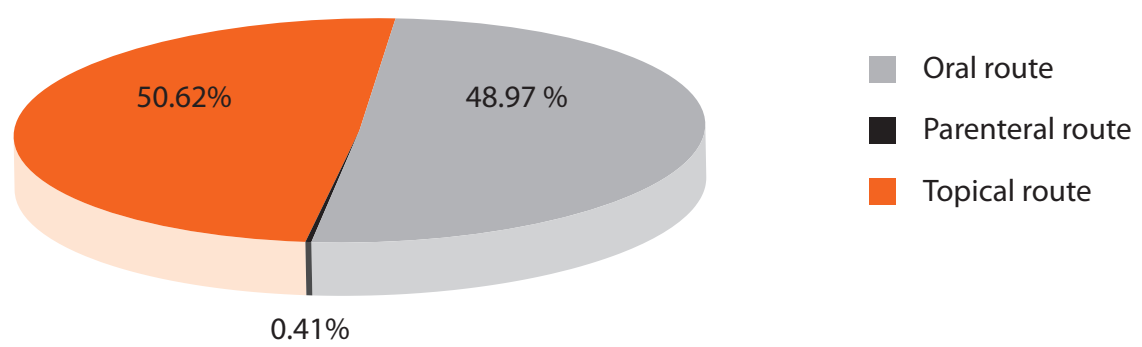

Figure 2: Commonly encountered routes of drug administration

Table 1: Common skin diseases encountered at KMCTH, Duwakot $(n=300)$

\begin{tabular}{|c|c|c|c|}
\hline S.N. & Disease & Frequency & Percentage \\
\hline 1 & Dermatitis & 50 & 16.7 \\
\hline 2 & Tinea & 43 & 14.3 \\
\hline 3 & Urticaria & 31 & 10.3 \\
\hline 4 & Acne & 19 & 6.3 \\
\hline 5 & Scabies & 13 & 4.3 \\
\hline 6 & PMLE & 12 & 4.0 \\
\hline 7 & Follicullitis & 11 & 3.7 \\
\hline 8 & Eczema & 11 & 3.7 \\
\hline 9 & Impetigo & 10 & 3.3 \\
\hline 10 & Herpes & 9 & 3.0 \\
\hline 11 & Melasma & 8 & 2.7 \\
\hline 12 & Insect bite reaction & 8 & 2.7 \\
\hline 13 & Pityriasis alba & 6 & 2.0 \\
\hline 14 & $\begin{array}{l}\text { Lichen simplex } \\
\text { chronicus }\end{array}$ & 5 & 1.7 \\
\hline 15 & Pityriasis versicolor & 4 & 1.3 \\
\hline 16 & Candidiasis & 4 & 1.3 \\
\hline 17 & Verruca & 4 & 1.3 \\
\hline 18 & Miliaria & 3 & 1.0 \\
\hline 19 & Psoriasis & 3 & 1.0 \\
\hline 20 & Alopecia areata & 3 & 1.0 \\
\hline 21 & Fissured feet & 3 & 1.0 \\
\hline 22 & $\begin{array}{l}\text { Molluscum } \\
\text { contagiosum }\end{array}$ & 3 & 1.0 \\
\hline 23 & Abscess & 3 & 1.0 \\
\hline 24 & Chelitis & 3 & 1.0 \\
\hline 25 & Others & 31 & 10.3 \\
\hline
\end{tabular}

Table 2: Frequently prescribed drug categories $(n=729)$

\begin{tabular}{|clcc|}
\hline S.N. & Drug Groups* & Frequency & Percentage \\
\hline 1 & Antihistaminics & 209 & 28.7 \\
\hline 2 & Antibiotics & 108 & 14.8 \\
\hline 3 & Antifungal & 108 & 14.8 \\
\hline 4 & Corticosteroids & 123 & 16.9 \\
\hline 5 & Antiacne & 29 & 4.0 \\
\hline 6 & Moisturiser & 27 & 3.7 \\
\hline 7 & Keratolytics & 25 & 3.4 \\
\hline 8 & Antihelminthics & 16 & 2.2 \\
\hline 9 & Sunscreen & 15 & 2.1 \\
\hline 10 & Scabicidals & 14 & 1.9 \\
\hline 11 & Chelating agents & 13 & 1.8 \\
\hline 12 & Fibrinolytics & 8 & 1.1 \\
\hline 13 & NSAIDs & 8 & 1.1 \\
\hline 14 & Others & 26 & 3.6 \\
\hline
\end{tabular}

Table 3: Different dosage forms prescribed

\begin{tabular}{|llcc|}
\hline $\begin{array}{l}\text { Route of } \\
\text { Administration }\end{array}$ & $\begin{array}{l}\text { Dosage } \\
\text { form }\end{array}$ & Frequency & $\begin{array}{c}\text { Percentage } \\
\text { (\%) }\end{array}$ \\
\hline \multirow{3}{*}{ Oral } & Capsule & 66 & 9.05 \\
& Syrup & 36 & 4.94 \\
\hline Parenteral & Tablet & 255 & 34.97 \\
& Injection & 3 & 0.41 \\
\hline \multirow{3}{*}{ Topical } & Cream & 234 & 32.09 \\
& Face wash & 10 & 1.37 \\
& Gel & 28 & 3.84 \\
& ointment & 42 & 5.76 \\
& Lotion & 39 & 5.34 \\
& Shampoo & 16 & 2.19
\end{tabular}


Table 4: Total number of drugs per prescription

\begin{tabular}{lc}
\hline Descriptive Statistics & Measure \\
\hline Total no of prescription & 300 \\
\hline Maximum number of drugs prescribed & 5 \\
\hline Minimum number of drugs prescribed & 1 \\
Mean \pm SD & $2.42 \pm 0.82$ \\
\hline
\end{tabular}

\section{DISCUSSION}

Pattern of skin diseases in developing countries like Nepal is influenced by the economy, level of literacy, social backwardness, varied climate, occupation, access to primary health care, and different religious, ritual and cultural factors. ${ }^{1}$ Nowadays, it is important to study the prevalence of skin diseases from the point of view of public health as the factors associated with high prevalence of skin diseases include low socioeconomic status, malnutrition, and poor standards of hygiene, limited access to health care facilities ${ }^{3-4}$.

In this study it was found that the most commonly female patients were affected with skin diseases. This is because the female population in Nepal is more than the male population and females are equally exposed to the causative factors of skin diseases as males, as they share the same working environment. This finding is similar to different studies in South India conducted by Kuruvilla et al., Yuwnate $\mathrm{AH}$ et al, Joel JJ et al. ${ }^{2,6-7}$. This study showed that the most common age group affected by skin diseases is the age group between $20-60$ years (57\%), as this age group is mostly exposed to the aggravating factors that serve as the reason for skin diseases.

In the current study, antihistaminics (28.7\%) were found to be the commonly prescribed drugs which are similar to the study conducted by Joel J.J.et al. ${ }^{2}$ and Thawani et al in south India where the commonly prescribed drugs for skin diseases were antihistamines (25.6\%). However, another study conducted by Yuwante $\mathrm{AH}$ et al. ${ }^{7}$ and Sweileh WM et al. ${ }^{5}$ in Wardha district of India, showed that antifungals were the most commonly prescribed drugs .This is because of difference in the disease prevalence between the different study areas.

This study showed that the most common disease pattern seen in patients attending the dermatology OPD was primarily dermatitis, which is different from study conducted by Das KK et al. who reported eczema (23.10\%), as the major skin disease. Eczema and dermatitis are both similar terms often used concomitantly except when the inflammation part is there the term dermatitis can be used. Eczema is associated with $\lg E$ and is more common in children up to 5years of age whereas dermatitis is not always associated with $\lg \mathrm{E}^{13}$. Narwane et al. in Mumbai reported pyoderma (19\%) as most common skin ailment while Devi B and Zamzachin G in a study conducted in Imphal reported eczema $(23.10 \%)^{8-}$ ${ }^{10}$.The difference in the results were due to the variation in the geographical location as well as difference in the socio-economic status of the patients. This study was conducted in Duwakot which is a sub urban area. The patients visiting the dermatology OPD were farmers and those working in brick factories. So, this is one of the reasons for dermatitis being the most common skin disorder in our patient population

Among the total number of drugs prescribed, most of them were prescribed by topical followed by oral routes. The reason for high percentage of topical drugs being prescribed is that topical route has minimum side effects, site specific action and is convenient for patient use. This was comparable with the study conducted in India by Pathak AK et al. where topical dosage forms prescribed were $51.93 \%$ followed by oral $47.11 \%^{12}$.

In 300 prescriptions analyzed in this study, mean number of drugs per prescription was found to be $2.42 \pm 0.82$, which was slightly higher than the WHO recommended values 1.6 - 1.8 drugs per prescription. A total of 17 prescriptions had multiple diagnoses which included cases of allergic dermatitis with secondary bacterial infection, insect bite reaction with secondary bacterial infection, etc. Due to the multiple diagnoses, the average number of drugs prescribed is slightly higher than the WHO recommended values. This study showed that most of the patients received multidrug therapy as compared to single drug therapy. It is preferable to keep the average number of drugs per prescription as low as possible since higher figures always lead to increased risk of drug interactions, adverse drug reactions and poor medication compliance.

\section{CONCLUSION}

This current study describes the pattern of skin diseases that were commonly encountered in KMCTH, Duwakot and the various categories of drugs prescribed for the treatment of these conditions. Antihistaminics and antifungal drugs were widely used in this study which suggests that allergies and fungal infections are common in this area. This study also showed that the practice of poly-pharmacy was minimal which is a good practice. It is also concluded that more researches need to be conducted in Duwakot in order to find out the proper health status of people living there. 


\section{REFERENCES}

1. Grover S, Ranyal KR, Bedi KM. A cross section of skin diseases in rural Allahabad. Indian J Dermatol. 2008;53(4):179-81. [PubMed]

2. Joel JJ, Jose N, Shastry CS. Patterns of Skin Disease and Prescribing Trends in Rural India. Sch. Acad. J. Pharm. 2013; 2(4):304-9. [DOI]

3. Dogra S, Kumar B. Epidemiology of skin diseases in school children: A study from Northern India. PediatrDermatol. 2003;20:470-3. [DOI]

4. Rao C, Rao R. A Cross-Sectional Study of Dermatological Problems among Differently-Abled Children. Indian J Dermatol. 2012; 57(1):35. [DOI]

5. Sweileh WM. Audit of prescribing practices of topical corticosteroids in outpatient dermatology clinics in north Palestine. East Mediterr Health J. 2006; 12(1):161-9. [PubMed]

6. Kuruvilla M, Sridhar KS, Kumar P, Rao GS. Pattern of skin diseases in Bantwal Taluq, Dakshina Kannada. Indian J DermatolVenereolLeprol. 2000; 66(5):2478. [PubMed]

7. Yuwnate $\mathrm{AH}, \mathrm{Chandane}$ RD, Giri KR. A multicenter pharmacoepidemiological study of dermatological disorders in Wardha district. Int J Basic ClinPharmacol. 2013;2:751-6. [FullText]
8. Das KK. Pattern of dermatological diseases in Guwahati Medical College and hospital Guwahati. Indian J DermatolVenereolLeprol. 2003; 69(I) 6-8. [FullText]

9. Narwane SP, Patel TC, Shetty YC, Chikhalkar SB. Drug utilization and cost analysis for common skin diseases in dermatology OPD of an Indian tertiary care Hospital- A prescription survey. Br J Pharm Res. 2011; 1(1):918. [FullText]

10. Devi B, Zamzachin G. Pattern of skin diseases in Imphal. Indian J Dermatol. 2006; 51(2):149-50. [FullText]

11. Sarkar C, Das B, Sripathi H. Drug prescribing pattern in dermatology in a teaching hospital in western Nepal. Journal of Nepal Medical Association January-March 2002; 41: 241-246.

12. Pathak AJ, Kumar S, Kumar M, Mohan L.Study of drug utilization pattern for skin diseases in dermatology OPD of an Indian tertiary care hospital - A Prescription Survey.J ClinDiagn Res. 2016 ; 10(2):1-5. [PubMed]

13. Kumar P, Clark M. Kumar and Clark's. Cinical Medicine. $9^{\text {th }}$ ed. London: Elsevier; $2017.1349 p$

14. WHO. How to investigate drug use in health facilities: selected drug use indicators.Geneva: World Health Organization.WHO/DPA.1993;1:1-87. 